Syntax Fusion : Jurnal Nasional Indonesia

p-ISSN: -

e-ISSN : 2775-4440

Vol. 1, No. 3, Maret 2021

\title{
ANALISIS KERENTANAN KEAMANAN WEBSITE MENGGUNAKAN METODE OWASP (OPEN WEB APPLICATION SECURITY PROJECT) PADA DINAS TENAGA KERJA
}

\author{
Dewi Aryanti, Nurholis dan Joy Nashar Utamajaya \\ Sistem Informasi, STMIK Borneo Internasional Balikpapan \\ Email: dewi.19@stmik-borneo.ac.id,nurholis.19@stmik-borneo.ac.id, \\ joy.nashar@stmik-borneo.ac.id
}

\begin{abstract}
Abstrak
Dinas Tenaga Kerja dan Transmigrasi merupakan organisasi perangkat daerah yang memiliki websiste sebagai media yang menampilkan secara interaktif jurnal informasi dan pembangunan daerah, media interaksi antara masyarakat dengan pemerintah. Terjadinya transisi komunikasi secara tradisional ke dalam lingkup aplikasi berbasis website bisa saja dimanfaatkan oleh beberapa pelaku kejahatan dunia maya dengan tujuan mencuri informasi rahasia pengguna dengan tujuan tertentu, maka mendeteksi kerentanan keamanan website adalah hal yang sangat penting Untuk mengetahui tingkat risiko pada sistem informasi harga komoditas utama menggunakan metode Open Web Application Security Project (OWASP) Risk Rating untuk mendeteksi kerentanan keamanan pada aplikasi berbasis website. Penelitian ini menghasilkan 2 faktor untuk memperkirakan Likelihood dan Impact, dari masing-masing faktor terdapat 3 risiko yang ditemukan yaitu risk severity High, risk severity Medium dan risk severity Low. Hasil penilaian risiko ini dapat membantu para pengelola dan pengembang sistem untuk menyadari risiko yang mungkin terjadi sehingga dapat mengambil tindakan untuk mencegah dan mengatasi risiko tersebut.
\end{abstract}

Kata Kunci: Tingkat risiko, OWASP, Asesmen risiko

\section{Pendahuluan}

Pengujian sistem keamanan aplikasi berbasis website adalah hal yang penting di era perkembangan aplikasi berbasis web yang melaju dengan pesat. Semakin berkembangnya aplikasi berbasis web juga diiringi dengan tingginya serangan keamanan dari berbabagai teknik ancaman. Seringkali masalah keamanan berada di urutan kedua, atau bahkan diurutan terakhir dalam daftar hal-hal yang dianggap penting [1]. Oleh karena itu organisasi perlu melakukan asesmen pada aplikasi berbasis website agar oraganisasi mampu mendeteksi kerentanan dan memahami risiko yang dihadapi. Salah satu metode 
untuk penilaian tingkat risiko kerentanan keamanan aplikasi berbasis website adalah OWASP Risk Rating Methodology

Langkah besar dalam mengukur tingkat risiko adalah menentukan dampak buruk yang dihasilkan dari analisa kerentanan [2]. Hasil dari analisa kerentanan dapat membantu pengelola dan pengembang sistem untuk mencegah dan mengatasi dampak risiko yang ditemukan pada sistem. Belum adanya Security Assessment pada sistem informasi yang dibangun oleh pihak DisnakerTrans. Saat ini dalam membangun sistem tersebut dengan mengandalkan library untuk mengamankan sistem. Namun dengan menerapkan library belum diiringi dengan pengujian sistem secara langsung dari internal perusahaan, sehingga belum mengetahui secara pasti celah keamanan sistem yang sudah dibangun. Oleh karena itu perlu adanya Security Assessment (Penilaian keamanan) pada sistem tersebut

Ada beberapa faktor yang menyebabkan kurangnya tingkat keamanan pada aplikasi website, diantaranya adalah kesalahan penulisan kode program dan misconfigutation [3]. Kesalahan pada penulisan kode program dalam pembuatan aplikasi berbasis website sering dimanfaatkan oleh penyerang, dalam hal ini serangan yang sering dimanfaatkan oleh penyerang diantaranya adalah SQL Injection, Authentication dan XSS [4]. Seperti pada diagram statistik yang dirilis oleh webappsec.org (diperbaharui pada januari 2010) pada Gambar 1 menunjukan bahwa SQL Injection (26.38\%) dan XSS (35.57\%) merupakan jenis serangan yang sering digunakan [5].

\section{Percentage of websites vulnerable by class (Top 5)}

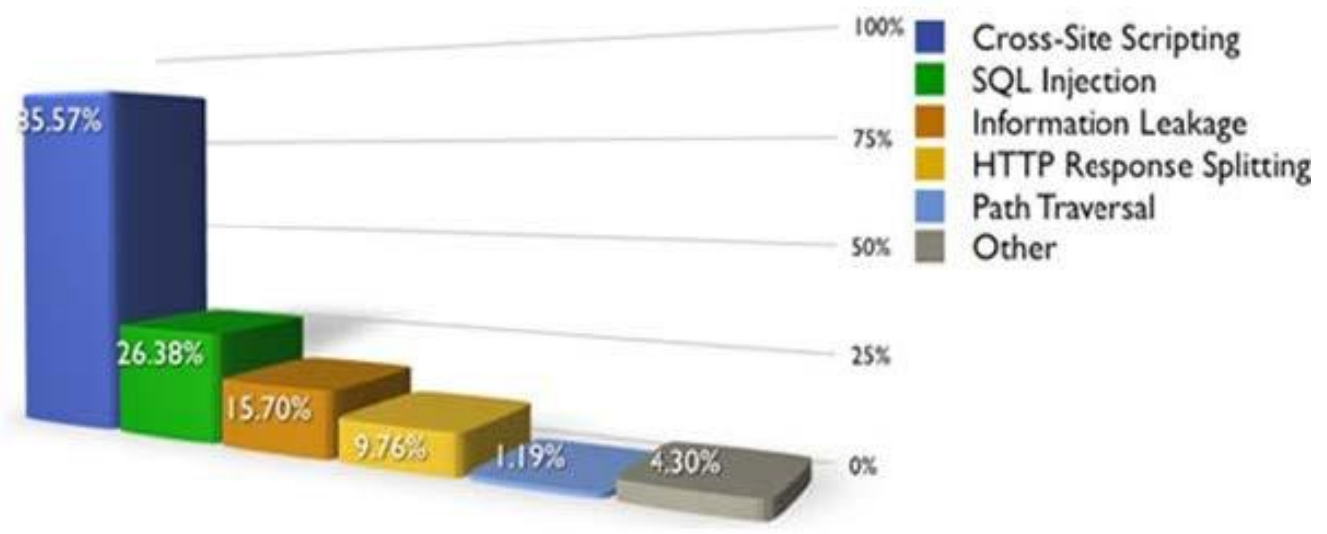

Gambar 1. Prosentase kerentanan website

Pada penelitian ini, untuk mendeteksi kerentanan keamanan terdapat beberapa metode diantaranya: ISSAF, OSSTMM, OWASP, NIST [6]. Namun diantara ketiga metode tersebut yang tepat untuk penetration testing adalah OWASP [7]. OWASP juga dikenal sebagai organisasi non- profit amal di Amerika Serikat berdiri pada tahun 2004 dan dilengkapi standart Guide untuk mempermudah penetration testing. 


\section{Metode Penelitian}

Metodologi penilaian risiko OWASP adalah pendekatan sederhana untuk menghitung dan menilai risiko yang terkait dengan aplikasi. dimana dengan metode tersebut dapat diputuskan apa saja yang harus dilakukan terhadap resiko-resiko tersebut [8]. Dengan mengetahui resiko yang akan terjadi maka banyak manfaat yang akan diperoleh diantaranya, menghemat waktu dan mengurangi terjadinya resiko yang lebih serius. Perkiraan resiko pada metodologi OWASP dimulai dengan model:

Risk $=$ Likelihood $*$ Impact

Dimana:

Likelihood : Kemungkinan kerentanan untuk menjadi dieksploitasi oleh penyerang.

Impact : Dampak dari serangan yang yang berhasil sukses.

Risk : Kemungkinan risiko yang terkait dengan faktor ancaman, kerentanan, dampak teknis dan bisnis.

Sedangkan Untuk persamaan formulasi teorema matematika menggunakan persamaan i:

$\mathrm{x}=\left(\sum \mathrm{x}\right) / \mathrm{n}$

(1)

Dimana:

$x$ : nilai Rata-rata hitung (Risk)

$\Sigma x$ : nilai sampel (skor penilaian)

$n$ : Jumlah sampel (Jumlah vulnerability)

Menurut OWASP terdapat beberapa tahap untuk menentukan dan mengkombinasikan besarnya resiko yang ditimbulkan akibat eksploitasi kelemahan yang terdapat pada suatu aplikasi web, Berikut tahapan OWASP Risk Rating Methodology yaitu Identifying a Risk, Factors for Estimating Impact, Determining the Severity of the Risk, Deciding What to Fix, Customizing the Risk Rating Model.

\section{A. Action Research}

Metode penelitian yang digunakan dalam penelitian ini menggunakan metode penelitan tindakan atau action research, ada lima tahapan dalam penelitian yang merupakan siklus dari action research. Tahap pertama adalah melakukan diagnosa (Diagnosing) Pada tahapan ini peneliti akan melakukan identifikasi masalah-masalah yaitu: diagnosa sistem keamanan pada aplikasi berbasis web yang dibangun DisnakerTrans.

Tahap kedua adalah membuat rencana tindakan (Action Planning) tahapan ini peneliti melakukan pemahaman pokok masalah yang ada dan menyusun rencana tindakan yang tepat untuk menyelesaikan masalah yang ada. Peneliti akan mulai menyusun rencana pengujian yang akan dilakukan.

Tahap ketiga adalah melakukan tindakan (Action Taking) mengimplementasikan rencana tindakan yang telah disusun. Pada langkah ini peneliti mulai melakukan tahapan- 
Dewi Aryanti, Nurholis dan Joy Nashar Utama Jaya

tahapan investigasi guna mendapatkan informasi kelemahan sistem dan mengujinya secara langsung dengan menggunakan tipe-tipe ancaman.

Tahap keempat adalah melakukan evaluasi (Evaluating) setelah tahapan Action Taking dilaksanakan peneliti mulai melakukan evaluasi pada hasil dari implementasi sebelumnya dan mulai menyimpulkan hasil dari langkah sebelumnya.

Tahap kelima adalah pembelajaran (Learning) langkah ini merupakan tahap akhir dari penelitian yaitu melakukan review terhadap hasil dari tahapan-tahapan yang telah dilalui.Hasil dan Pembahasan.

B. Alur Penelitian

Alur penelitian merupakan langkah yang harus dilakukan dalam penelitian hingga mencapai suatu kesimpulan. Adapun alur penelitian yang penulis gunakan seperti yang terlihat pada Gambar 2.

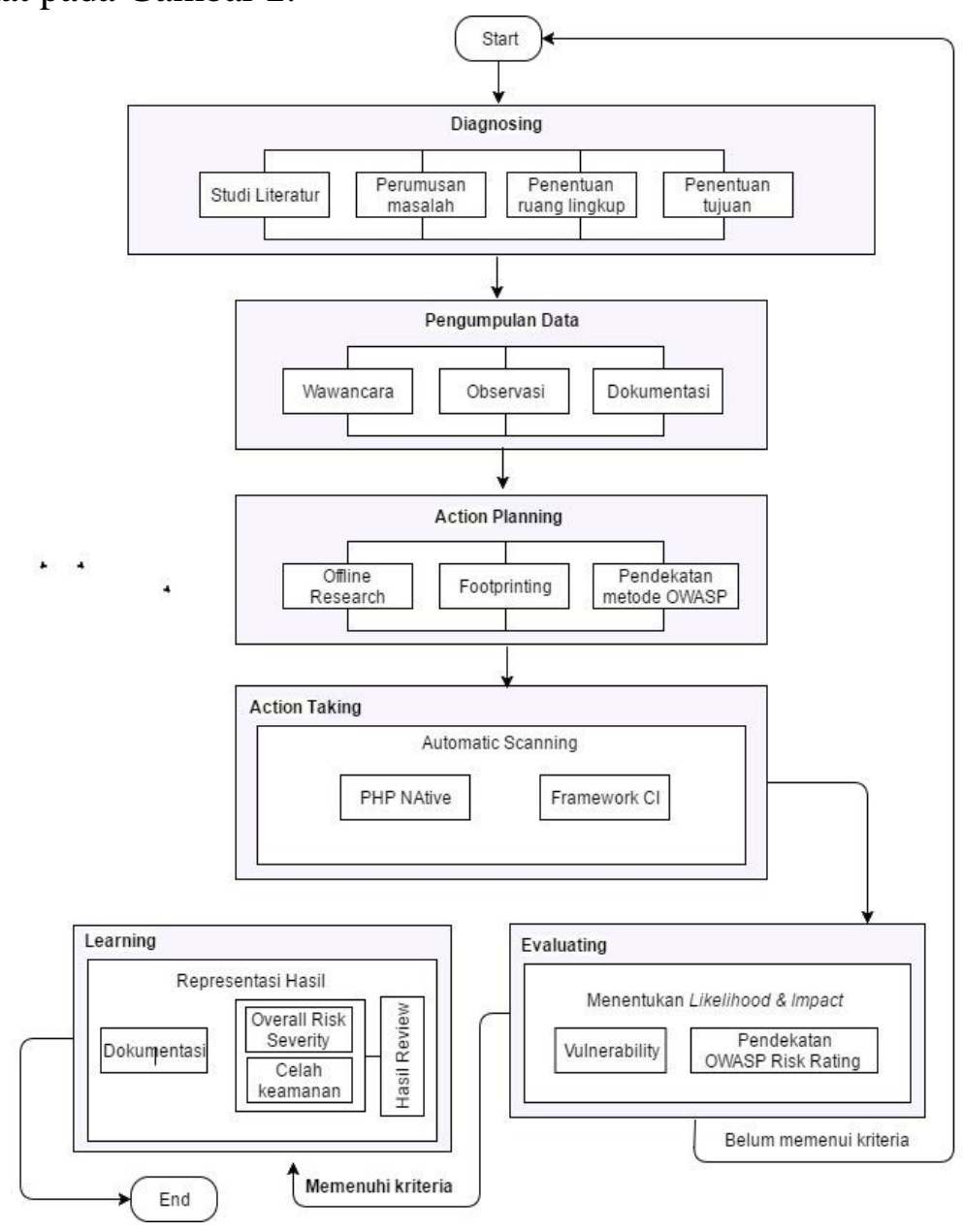

Gambar 2. Alur Penelitian 


\section{Hasil dan Pembahasan}

Mendeteksi kerentanan pada penelitian ini menggunakan aplikasi Acunetix untuk mengetahui celah keamanan yang ada di aplikasi berbasis website. Dimana pengembangan aplikasi website yang sudah dibangun menggunakan PHP Native dan Framework CI (CodeIgniter) sebagai platform web application development. Gambar 3 adalah tampilan hasil scanning Menggunakan Tools Acunetix Web Vulnerability Scanner.

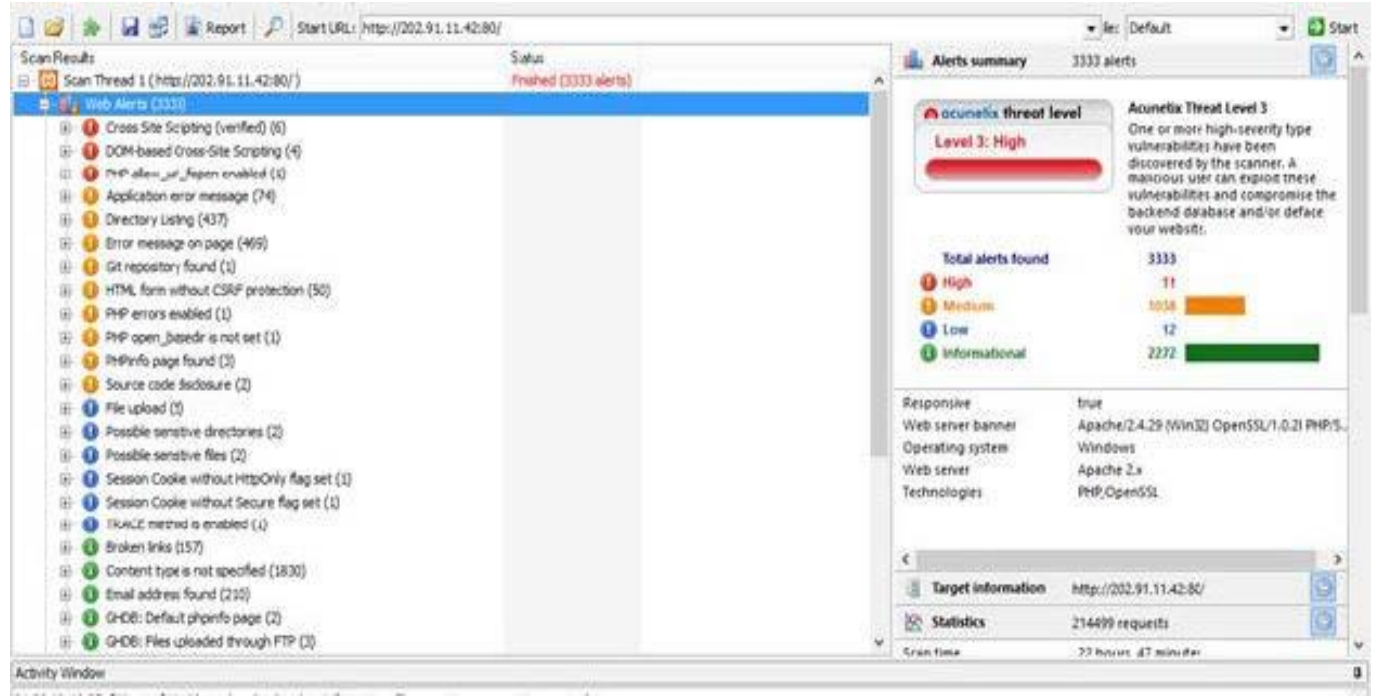

Gambar 3. Tools Acunetix Web Vulnerability Scanner

Setelah dilakukan proses scaning. Pada tabel 1 akan menunjukan celah keamanan yang ada di sistem informasi.

Tabel 1. Celah keamanan yang ditemukan

\begin{tabular}{ll}
\hline Domain & Kerentanan \\
\hline & Cross Site Scripting \\
\cline { 2 - 2 } http:/ & PHP allow_url_fopen \\
88 & enabled \\
\cline { 2 - 3 } & Error message on page \\
\cline { 2 - 2 } & Directory Listing \\
\cline { 2 - 2 } & HTML form without \\
& CSRF protection \\
\hline & Session Cookie without \\
& HttpOnly flag set \\
\cline { 2 - 3 } & Possible sensitive \\
& directories \\
\hline & Possible sensitive files \\
\hline & Possible sensitive files \\
\hline & Cross Site Scripting \\
\hline & PHP allow_url_fopen \\
& enabled \\
\hline
\end{tabular}




\begin{tabular}{ll}
\hline http:// & Error message on page \\
\cline { 2 - 2 } 111.68.119.1 & Directory Listing \\
\cline { 2 - 2 } & HTML form without \\
& CSRF protection \\
\cline { 2 - 2 } & Session Cookie without \\
& HttpOnly flag set \\
\cline { 2 - 2 } & Slow response time \\
\hline
\end{tabular}

Berdasarkan metodologi OWASP Risk Rating terdapat beberapa tahapan untuk menentukan dan mengkombinasikan besarnya resiko yang ditimbulkan, tahapan tersebut diantaranya Threat Agent Factors, Vulnerability Factors dan Technical Impact.

\section{A. Threat Agent Factors}

Kumpulan faktor pertama terkait dengan Threat agent yang terlibat. Tujuannya adalah untuk memperkirakan kemungkinan serangan yang berhasil oleh kelompok threat agent. Berikut kriteria untuk memperkirakan Likelihood kelompok Threat agent factors antara lain [9]:

1. Skill level

Seberapa terampil secara teknis kelompok threat agent? Keterampilan penetrasi keamanan (9), keterampilan jaringan dan pemrograman (6), pengguna komputer tingkat lanjut (5), beberapa keterampilan teknis (3), tidak ada keterampilan teknis (1)

\section{Motive}

Seberapa kelompok Threat Agent termotivasi untuk menemukan dan memanfaatkan kerentanan ini? Tidak ada reward (1), memungkinkan mendapat reward (4), mendapatkan reward yang tinggi (9).

\section{Opportunity}

Sumber daya apa yang dibutuhkan kelompok threat agent untuk menemukan dan memanfaatkan kerentanan ini? Akses penuh atau membutuhkan sumber daya yang mahal (0), akses khusus atau sumber daya yang dibutuhkan (4), beberapa akses atau sumber daya yang dibutuhkan (7), tidak ada akses atau sumber daya yang diperlukan (9).

4. Size

Seberapa besar kelompok threat agent? Pengembang (2), administrator sistem (2), pengguna intranet (4), mitra (5), pengguna terotentikasi (6), pengguna internet anonim (9).

Tabel 2. Skor Threat Agent Factor

\begin{tabular}{lcccc}
\hline Jenis Ancaman & Skill level & Motive & Oppurtunity & Size \\
\hline Cross Site Scripting & 9 & 9 & 4 & 9 \\
\hline PHP allow_url_fopen enabled & 9 & 9 & 4 & 9 \\
\hline Application Error message & 6 & 4 & 9 & 2 \\
\hline Directory Listing & 6 & 3 & 4 & 9 \\
\hline
\end{tabular}




\begin{tabular}{lllll}
\hline $\begin{array}{l}\text { HTML form without CSRF } \\
\text { protection }\end{array}$ & 9 & 4 & 7 & 9 \\
\hline $\begin{array}{l}\text { Session Cookie without HttpOnly } \\
\text { flag set }\end{array}$ & 6 & 4 & 4 & 6 \\
\hline $\begin{array}{l}\text { Slow response time } \\
\text { http://111.68.119.188 }\end{array}$ & 6 & 4 & 9 & 9 \\
\hline Cross Site Scripting & 9 & 9 & 4 & 9 \\
\hline PHP allow_url_fopen enabled & 9 & 9 & 4 & 9 \\
\hline Error message on page & 6 & 4 & 9 & 2 \\
\hline Directory Listing & 6 & 3 & 4 & 9 \\
\hline $\begin{array}{l}\text { HTML form without CSRF } \\
\text { protection }\end{array}$ & 9 & 4 & 7 & 9 \\
\hline $\begin{array}{l}\text { Session Cookie without HttpOnly } \\
\text { llag set }\end{array}$ & 6 & 4 & 4 & 6 \\
\hline Possible sensitive directories & 5 & 4 & 9 & 9 \\
\hline Possible sensitive files & 5 & 4 & 9 & 9 \\
\hline
\end{tabular}

\section{Vulnerability Factors}

Faktor selanjutnya adalah terkait dengan vulnerability yang terlibat. Dengan Tujuan untuk memperkirakan kemungkinan vulnerability tertentu yang terlibat ditemukan dan dieksploitasi. Asumsikan dengan threat agent yang sudah dipilih. Berikut kriteria untuk memperkirakan Likelihood kelompok vulnerability factors antara lain [10]:

\section{Ease of discovery}

Seberapa mudah bagi kelompok threat agent untuk menemukan kerentanan ini? cara Praktis tidak mungkin (1), sulit (3), mudah (7), alat otomatis tersedia (9).

\section{Ease of exploit}

Seberapa mudah bagi kelompok threat agent untuk benar-benar memanfaatkan kerentanan ini? Alat bantu otomatis teoritis (1), sulit (3), mudah (5), tersedia (9).

\section{Awareness}

Seberapa terkenal kerentanan ini terhadap kelompok threat agent? Tidak diketahui (1), tersembunyi (4), jelas (6), pengetahuan umum (9).

\section{Intrusion detection}

Seberapa besar kemungkinan exploit untuk dideteksi? Deteksi aktif dalam aplikasi (1), login dan ditinjau (3), login tanpa review (8), tidak login (9).

Berikut adalah hasil pilihan faktor vulnerability yang sudah disediakan oleh OWASP risk rating, seperti pada Tabel 3.

Tabel 3. Skor Vulnerability Factors 
http://111.68.119.188/CI

\begin{tabular}{lllll}
\hline Jenis Ancaman & EoD & EoE & Aw & ID \\
\hline Cross Site Scripting & 9 & 5 & 9 & 1 \\
\hline PHP allow_url_fopen enabled & 9 & 3 & 4 & 1 \\
\hline Application Error message & 9 & 3 & 4 & 1 \\
\hline Directory Listing & 9 & 3 & 4 & 1 \\
\hline $\begin{array}{l}\text { HTML form without CSRF } \\
\text { protection }\end{array}$ & 9 & 3 & 9 & 1 \\
\hline $\begin{array}{l}\text { Session Cookie without HttpOnly } \\
\text { flag set }\end{array}$ & 9 & 3 & 9 & 1 \\
\hline $\begin{array}{l}\text { Slow response time } \\
\text { http://111.68.119.188 }\end{array}$ & 9 & 5 & 9 & 1 \\
\hline Cross Site Scripting & & & & \\
\hline PHP allow_url_fopen enabled & 9 & 5 & 9 & 1 \\
\hline Application Error message & 9 & 3 & 4 & 1 \\
\hline Directory Listing & 9 & 3 & 4 & 1 \\
\hline $\begin{array}{l}\text { HTML form without CSRF } \\
\text { protection }\end{array}$ & 9 & 3 & 4 & 1 \\
\hline $\begin{array}{l}\text { Session Cookie without HttpOnly } \\
\text { flag set }\end{array}$ & 9 & 3 & 9 & 1 \\
\hline Possible sensitive directories & 9 & 3 & 4 & 1 \\
\hline Possible sensitive files & 9 & 3 & 4 & 1 \\
\hline
\end{tabular}

C. Technical Impact

Tujuan utama dari dampak teknis adalah menghitung besarnya dampak jika kerentanan dieksploitasi dari aplikasi. Faktor dampak teknis lebih jauh dibagi menjadi empat kelas yaitu kerahasiaan, integritas, ketersediaan dan akuntabilitas Tujuan informasi Sistem keamanan adalah untuk melindungi kerahasiaan, integritas, tersedianya. Dengan demikian faktor dampak teknis memainkan peran utama dalam penilaian risiko aplikasi. Dampak teknisnya adalah perkiraan jumlah faktor teknis ini dengan memberikan kecocokan bobot faktor individu. Berikut kriteria untuk memperkirakan Technical impact antara lain:

\section{Loss of confidentiality}

Berapa banyak data yang bisa diungkapkan dan seberapa sensitif? Data yang diungkapkan minimum dan tidak sensitif (2), minimal data kritis yang diungkapkan (6), data non-sensitif ekstensif yang diungkapkan (6), data kritis dan ekstensif diungkapkan (7), semua data yang diungkapkan (9). 


\section{Loss of integrity}

Berapa data yang bisa rusak dan seberapa rusaknya? Data korup yang minimal sedikit (1), data korup minimal yang serius (3), data yang agak korup sekali, (7), semua data benar-benar korup (9).

3. Loss of availability

Berapa banyak layanan yang bisa hilang dan seberapa vitalnya? Layanan sekunder minimal terputus (1), layanan primer minimal terputus (5), layanan sekunder yang luas terganggu (5), layanan utama yang luas terganggu (7), semua layanan benar-benar hilang (9).

\section{Loss of accountability}

Apakah tindakan agen ancaman bisa dilacak pada individu? Sepenuhnya dapat dilacak (1), mungkin dapat dilacak (7), benar-benar anonim (9).

Rumus untuk mendapatkan hasil Technical Impact secara keseluruhan mengikuti OWASP Risk Rating Methodology menggunakan persamaan 4:

$$
\text { technical impact }=\frac{\begin{array}{l}
\text { Confidentiality }+ \text { Integrity }+ \\
\text { Availability }+ \text { Accountability }
\end{array}}{4}
$$

Berikut hasil dari skor penilaian Technical impact, seperti pada table 4.

\begin{tabular}{|c|c|c|c|c|}
\hline \multicolumn{5}{|c|}{ http://111.68.119.188/CI } \\
\hline Jenis Ancaman & LoC & LoI & LoA & LoAV \\
\hline Cross Site Scripting & 2 & 1 & 1 & 9 \\
\hline $\begin{array}{l}\text { PHP allow_url_fopen } \\
\text { enabled }\end{array}$ & 6 & 3 & 1 & 7 \\
\hline Application Error message & 2 & 3 & 1 & 7 \\
\hline Directory Listing & 2 & 1 & 1 & 1 \\
\hline $\begin{array}{l}\text { HTML form without CSRF } \\
\text { protection }\end{array}$ & 6 & 3 & 1 & 9 \\
\hline $\begin{array}{l}\text { Session Cookie without } \\
\text { HttpOnly flag set }\end{array}$ & 2 & 3 & 1 & 7 \\
\hline Slow response time & 2 & 1 & 1 & 7 \\
\hline \multicolumn{5}{|l|}{ http://111.68.119.188/ } \\
\hline Cross Site Scripting & 2 & 1 & 1 & 9 \\
\hline $\begin{array}{l}\text { PHP allow_url_fopen } \\
\text { enabled }\end{array}$ & 6 & 3 & 1 & 7 \\
\hline
\end{tabular}

Tabel 4. Skor Technical Impact 
Dewi Aryanti, Nurholis dan Joy Nashar Utama Jaya

\begin{tabular}{lllll}
\hline Application Error message & 2 & 3 & 1 & 7 \\
\hline Directory Listing & 2 & 1 & 1 & 1 \\
\hline $\begin{array}{l}\text { HTML form without CSRF } \\
\text { protection }\end{array}$ & 6 & 3 & 1 & 7 \\
\hline $\begin{array}{l}\text { Session Cookie without } \\
\text { HttpOnly flag set }\end{array}$ & 2 & 3 & 1 & 7 \\
\hline $\begin{array}{l}\text { Possible sensitive } \\
\text { directories }\end{array}$ & 2 & 1 & 1 & 7 \\
\hline Possible sensitive files & 2 & 1 & 1 & \\
\hline
\end{tabular}

Skor secara keseluruhan Likelihood dan Impact dari sistem informasi adalah 5.8 dan 2.622 pada domain http://111.68.119.188/CI, sedangkan nilai skor domain http://111.68.119.188/ adalah 5.638 dan 2.577 berikut skor Likelihood dan Impact, seperti pada tabel 6.

Tabel 5. Hasil Threat Agent Factors

\begin{tabular}{cccccc}
\hline \multicolumn{5}{c}{ http://111.68.119.188/CI } \\
\hline Skill Level & Motive & $\begin{array}{l}\text { Oppor } \\
\text { tunity }\end{array}$ & Size & Total & Risk \\
\hline 7.28 & 5.28 & 5.85 & 7.57 & 25.98 & 6.495 \\
\hline 6.87 & 5.12 & http://111.68.119.188 & & \\
\hline
\end{tabular}

Kesimpulan

Berdasarkan hasil security assessment dengan menggunakan OWASP Risk Rating Methodology terhadap 2 sampel aplikasi berbasis website yang memiliki karakter aplikasi web yang berbeda maka dapat disimpulkan Perlu adanya penilaian risiko kerentanan keamanan terhadap aplikasi berbasis website agar bisa terlihat potensi risiko keamanan untuk mencegah dan mengatasi risiko keamanan sebelum aplikasi berbasis website di upload ke server dan terdapat 7 risiko dengan 3 risiko memiliki risk severity high, 2 risiko memiliki risk severity medium, 2 risiko memiliki risk severity low.

Berdasarkan kesimpulan ada beberapa saran untuk dilakukan penelitian diantaranya menggunakan metode yang lain untuk melengkapi OWASP atau menggabungkan dua metode antara OWASP dan Cobit, untuk melakukan Security Assessment sebaiknya juga dilakukan proses uji penetrasi sistem secara manual. Penetrasi manual membutuhkan proses dan waktu yang lama karena harus melakukan uji coba untuk menemukan dan membuktikan celah keamanan yang ada pada sistem. Serta aplikasi berbasis web yang dibangun dan akan dilakukan Security Assessment ada baiknya membandingkan antara Framework Codeigniter dan Laravel. 


\section{Bibliografi}

Aryasa, K., Paulus, Y. T., 2017, Implementasi Secure Hash Algorithm-1 Untuk Pengamanan Data Dalam Library Pada Pemrograman Java, Citec Journal, Vol. 1, No. 1, Hal 57 - 66.

Fernando, Y. I., Abdillah, R., 2016, Security Testing Sistem Penerimaan Mahasiswa Baru Universitas XYZ Menggunakan Open Source Security Testing Methodology Manual (OSSTMM), Jurnal CoreIT, Vol. 2, No.1, Hal 33 - 40.

Rafiq, A., Touseef, P., Ashraf, M. A., Analysis of Risks against Web Applications in MVC. NFC IEFR Journal of Engineering and Scientific Research, Vol. 5, No. 1, hal. 16

Hutagalung, R. H., Nugroho, L. E., Hidayat, R., 2017, Menentukan Dampak Resiko Keamanan Berbasis Pendekatan Owasp, Prosiding SNATI F Ke-4 Tahun 2017, Kudus, Indonesia.

uliharta, I. G. P. K., 2012, Business Impact Analysis Sistem dan Jaringan Komputer Menggunakan Metode Network Security Assessment, EKSPLORA INFORMATIKA, Vol. 2, No. 1, Hal 89 - 100.

Kesuma, M. C., Shiddiqi, A. M., Pratomo, B. A., 2013, Pencari Celah Keamanan pada Aplikasi Web, Tugas Akhir, Jurusan Teknik Informatika, Fakultas Teknologi Informasi, Institut Teknologi Sepuluh Nopember.

Web Application Security Consortium, http://www.webappsec.org/

Shanley, A., Johnstone, M. N., 2015, Selection of penetration testing methodologies: A comparison and evaluation, Australian Information Security Management Conference. Western Australia.

Rao, R. M., Durgesh, P., 2010, Security risk assessment of Geospatial Weather Information System (GWIS): An OWASP based approach, (IJCSIS) International Journal of Computer Science and Information Security, Vol. 8, No. 5, Hal $24-$ 32. 